\title{
Особенности регулирования цены по договору купли-продажи товаров в праве Китая (в сравнении с российским правом)
}

\author{
Медведев A.B. ${ }^{*}$
}

В настоящей работе автор продолжает рассмотрение некоторьх вопросов регулирования договора купли-продажи товаров в гражданском праве Китая. Хотелось бы напомнить, что первая статья, посвященная законодательному регламентированию данного договора в КНР, была опубликована в № 1 «Московского журнала международного права» за 2005 г. Данная работа призвана развить затронутую тему и рассказать читателям об особенностях регулирования китайским законодателем одного из наиболее интересных, по мнению автора, аспектов договора купли-продажи - цены на товары. В ней будет дана общая характеристика норм специального закона КНР, регламентирующего установление хозяйствуюшими субъектами цен на товары. Данная тема представляет несомненный исследовательский интерес, так как китайское законодательство по указанному вопросу носит специфический характер, отличаясь от законодательства других стран (в частности, России), в которых, как правило, нет отдельных базовых законов по данному вопросу. Таким образом, как представляется автору статьи, читателям будет полезно как с теоретической, так и с практической точек зрения рассмотреть, в каком направлении развивается регулирование этого вопроса в Китае - ведущей мировой державе, строящей оригинальную модель рыночной экономики с так называемой «социалистической китайской спецификой».

Если говорить о России, автору статьи известны, например, следующие нормативно-правовые акты, которыми регулиругтся цены на отдельные виды товаров: 1) Постановление Правительства РФ от 07.03.1995 г. (в редакции от 12.07.2005 г.) № 239 «О мерах по упорядочению государственного регулирования цен (тарифов)», которым утверждены Перечни продукции производственно-технического назначения, товаров народного потребления и услуг, на которые государственное регулирование цен (тарифов) на внутреннем рьнке Российс-

* Медведев Александр Владимирович - аспирант кафедры МЧиГП МПИМО (У) МИД России, юрист компании «Бритиш Американ Тобакко Россия). 
кой Федерации осуществляют Правительство РФ и федеральные органы исполнительной власти, а также органы исполнительной власти субъектов РФ; 2) Постановление Правительства РФ от 15.04.1995 г. (в редакции от 01.02.2005 г.) № 332 «О мерах по упорядочению государственного регулирования цен на газ и сырье для его производства», в соответствии с которым принято несколько подзаконных актов (в частности, приказов Минэкономразвития РФ), устанавливающих цены на указанные товары; 3) Закон г. Москвы от 28.01.2004 г. № 5 «О государственном контроле за соблодением порядка ценообразования и применения регулируемых цен», согласно которому в Москве осуществляется контроль за соблюдением порядка ценообразования на товары, цены на которые устанавливаются или регулируются уполномоченными на то государственными органами РФ и государственными органами города Москвы. В дальнейшем по ходу статьи автор предпримет попытку сравнения некоторых положений указанных правовых актов с нормами Закона КНР оценах.

Кроме того, можно отметить, что в 2000 году в Государственную Думу Федерального Собрания РФ был внесен проект Закона «Об основах ценообразования и организации контроля за ценами», который как раз и представлял собой аналогичный базовый закон по вопросу о регулировании установления в России хозяйствующими субъектами цен на свои товары. Однако в 2001 г. данный законопроект был отклонен, соответственно указанный закон так и не был принят.

Переходя к основной тематике настоящей статьи, хотелось бы приступить к рассмотрению вопроса об особенностях регулирования цены по договору купли-продажив праве КНР.

Цена на товар и обязанность ее уплаты являготся наиболее важными составляющими исполнения договора купли-продажи со стороны покупателя, что объясняет интерес автора к данной теме. Следует отметить, что помимо норм Закона о договорах (о которых автор уже рассказывал читателям в упоминавшейся вьше статье) в Китае существует специальный закон, регулирующий вопрос о ценах на товары (формирование, контроль и т.д.), который применяется и к договору купли-продажи. Это Закон КНР о ценах, принятый на 29-м заседании Постоянного комитета Всекитайского собрания народных представителей (ПК ВСНП) 8-го созыва 29.12.1997 г. и вступивший в силу c 01.05.1998 г. (далее- Закон КНР о ценах или Закон о ценах). Данный Закон был введен в действие вместо устаревшего Положения об ад- 
министративном регулировании цен 1987 г. и некоторых нормативноправовых актов Госсовета. Далее хотелось бы остановиться на ряде его положений, имеющих важное значение для более полного исследования и понимания темы настоящей статьи, и одновременно, насколько это возможно и применимо в целях настоящей работы, сравнить положения Закона о ценах с аналогичными нормами российского законодательства.

Для начала следует отметить, что Закон КНР о ценах «разработан в соответствии с потребностями в нормализации цен, повышении роли ценовых механизмов в процессе оптимального и рационального распределения материальных ресурсов, стабилизации общего уровня рыночных цен, защиты законных интересов потребителей и производителей, стимулирования здорового развития социалистической рыночной экономики» ${ }^{1}$. По смыслу ст. 2 Закона КНР о ценах стороны по договору купли-продажи при установлении цен в пределах КНР должны руководствоваться данным Законом. Согласно Закону о ценах, который делит их на цены на товары и расценки на услуги, цены на товары (регулирование которых как раз и будет рассмотрено в настоящей статье) - «это цены на продукцию различных видов и категорий, а также цены на интеллектуальную собственность»².

Кроме того, цены подразделяются также на: а) цены, регулируемые рынком (shichang tiaojie jia); б) цены, регулируемые правительством (zhengfu zhidaojia) и в) цены, устанавливаемые правительством (zhengfu guiding jia). Согласно ст. 3 Закона КНР ц ценах, регулируемые рынком цены - это цены, которые устанавливаются непосредственно хозяйствуюшими субъектами и совершенствуются в ходе рыночной конкуренции. Цены, регулируемые правительством, - это цены на товары, для которых правительственные органы в области ценообразования в соответствии с настоящим Законом, а также в соответствии со своимиполномочиями определяют базовую нормативную цену и границы, в пределах которых хозяйствующие субъьекты имеют право изменять данные цены. Цены же, устанавливаемые правительством, - это цены, которые в соответствии с положениями Закона КНР о ценах устанавливаются правительственными органами в области ценообразования в соответствии с полномочиями даншых ведомств при определении цен (ст. 3 Закона о ценах).

${ }^{1}$ Новое законодательство Китайской Народной Республики // Экспресс-информация. 2001. № 4/Составитель Гудошников Л.М. М.: РАН Институт Дальнего Востока. С. 71 . ${ }^{2}$ Там же. С. 71 . 
Согласно упоминавшемуся Закону КНР о договорах, в Китае существует несколько отраженных в данном Законе принципов заключения и исполнения договоров: а) принцип свободы воли сторон договора; б) принцип честности, добросовестности и доверия; в) принцип справедливости. Можно сказать, что в дополнение к этим принципам ст. 7 Закона КНР о ценах устанавливает следующее правило: «хозяйствующий субъект при определении цен должен придерживаться принципа справедливости, законности, честности и доверия»³ .

Статьями 8-10 Закона о ценах также предусматриваются некоторые принципы, которые действуют в отношении хозяйствующих субъектов при установлении цен на товары. При определении уровня цен они должны руководствоваться производственной себестоимостью продукции, а также учитьвать соотношение спроса и предложения на товар. Хозяйствующие субъькты также обязаны всесторонне совершенствовать производственно-хозяйственную деятельность, снижать себестоимость продукции, предлагать потребителям товары по рациональным ценам и получать законную прибыль в ходе рьночной конкуренции. Они также должны в соответствии со своими условиями хозяйствования создавать и совершенствовать систему внутреннего регулирования цен. При подготовке документации, в которой рассчитывается производственно-хозяйственная себестоимость товаров, субъектам рынка не разрешается прибегать к различным уловкам и фальсификациям.

Для сравнения: право России (Гражданский кодекс РФ - далее ГК РФ) содержит следующее положение (п. 3 ст. 485) о себестоимости в контексте установления цены на товар: «Если договор куплипродажи предусматривает, что цена товара подлежит изменению в зависимости от показателей, обусловливающих цену товара (себестоимость, затраты и т.п.), но при этом не определен способ пересмотра цены, цена определяется исходя из соотношения этих показателей на момент заключения договора и на момент передачи товара $)^{4}$. Стоит отметить, что это правило применяется, если иное не установлено ГК РФ, другим законом, иными правовыми актами или договором и не вытекаст из существа обязательства.

${ }^{3}$ Новое законодательство Китайской Народной Республики //Экспресс-информация. 2001 . № 4/Составитель Гудошников Л.М. М.: РАН Институт Дальнего Востока. С. 72. ${ }^{4}$ Гражданский кодекс РФ, ч.ч. 1, 2 и 3 (официальный текст). М.: Омега-Л, 2005. С. 167. 
В соответствии со ст. 11 Закона КНР о ценах хозяйствующие субъъекты имеют следующие права при определении цен:

1) самостоятельно устанавливать регулируемые рынком цены;

2) на товары, цены на которые регулируются правительством, устанавливать эти цены в указанном интервале по своему усмотрению;

3) устанавливать цены на пробные партии новых видов товаров, входящих в группу товаров, цены на которые регулируются или устанавливаются правительством, за исключением особо установленных видов товаров;

4) сообщать о всех действиях любых лиц, нарушающих законные права хозяйствующих субъектов самостоятельно определять цены на регулируемыс рынком товары.

Согласно ст. 14 Закона о ценах хозяйствующим субъектам запрещены следующие действия при определении уровня цен:

1) установление при взаимном сговоре нерационалыных цен, в результате чего происходит нарушение законных прав прочих хозяйствующих субъектов или потребителей;

2) продажа товаров по демпинговым ценам (qingxiao) ниже себестоимости в целях вытеснения конкурентов или захвата рынка (за исключением случаев, когда продажа ниже себестоимости разрешена законом для скоропортящихся, сезонных и скопившихся товаров), что может привести к нарушению нормального производственнохозяйственного порядка, нанести вред государственным интересам, а также законным интересам прочих хозяйствующих субъектов. В данном случае Закон о ценах дополняет положения Закона КНР 1993 г. о недобросовестной конкуренции и иных подзаконных актов, запрещающих хозяйствующим субъектам подобные действия, так как это может негативно сказаться на всем рынке потребительских и промьпшленньх товаров.

3) фальсификация и распространение информации о росте цен, искусственное взвинчивание цен, что может привести к необоснованному повышению их уровня;

4) использование ложных и вводящих в заблуждение методов при установлении цен для привлечения к заключению торговых сделок потребителей или других субъектов рынка;

5) осуществление во время поставок товаров ценовой дискриминации по отношению к прочим хозяйствующим субъектам, имеющим аналогичные условия, поставляющим аналогичные товары и предос- 
тавляющим аналогичные услуги. В Законе устанавливается, что «все операции на рынке ведутся на равных условиях»;

6) искусственное завышение или занижение сорта при продаже товаров (неправильное декларирование товаров), что приводит к завышению или занижению цены на них;

7) погоня за сверхприбылью (нелегальные спекуляции, нарушающие положения законов и иных нормативно-правовых актов), что приводит к получению отдельными хозяйственными субъектами незаконных и необоснованных особо высоких прибылей в ушерб другим субъектам рынка;

8) Прочие действия при определении цен, запреценные законами и другими нормативно-правовыми актами. Факты такой деятельности, как представляется, должны устанавливаться уполномоченными государственными органами в области ценообразования.

Также, согласно ст. 13 Закона о ценах, «Хозяйствующий субъект при продаже товаров, объявив цену, не имеет права ее повышать или взимать не зафиксированные в ценнике расходы» ${ }^{6}$.

Как видно из вышеуказанных запретов, еще одной особенностью Закона КНР о ценах является его в целом антимонопольный характер и направленность на защиту прав потребителей.

Для сравнения хотелось бы привести некоторые аналогичные положения российского законодательства, а именно Закона РФ от 22.03.1991 г. (в редакции от 07.03.2005 г.) № 948-I «О конкуренции и ограничении монополистической деятельности на товарных рьнках» (далее-Закон РФ о конкуренции) (который пока еще действует, хотя, насколько известно автору настоящей статьи, в настоящий момент обсуждается проект нового закона, который, вероятно, через некоторое время будет принят) в части недопущения хозяйствующими субъектами нарушений в сфере установления цен на товары. Согласно ст. 5 данного Закона, хозяйствующему субъекту, занимающему доминирующее положение на рынке ${ }^{7}$, запрещаются следующие действия:

а) изьятие товаров из обращения, целью или результатом которого является создание или поддержание дефицита на рьшке либо повьшение цен;

${ }^{5}$ Новоезаконодательство Китайской Народной Республики //Экспресс-информация. 2001. № 4/Составитель Гудошников Л.М. М.: РАН Ннститут Дальнего Востока. С. 90. ${ }^{6}$ Там же. С. 74.

${ }^{7}$ См. Методические рекомендации по определению доминирующего положения хозяйствующего субъекта на товарном рынке, утвержденные приказом ГКАП РФ от 3 июня 1994 г. № 67. 
б) нарушение установленного нормативными актами порядка ценообразования;

в) установление, поддержание монопольно высоких (низких) цен.

В соответствии со ст. 6 Закона РФ о конкуренции хозяйствующим субъектам, действующим на рынке одного товара (взаимозаменяемых товаров), запрещается вступать в соглашения или осуществлять согласованные действия, которые приводят (или могут привести) к:

а) установлению (подцержанию) цен (тарифов), скидок, надбавок (доплат), наценок;

б) повышению, снижению или поддержанию цен на аукционах и торгах.

Характерными примерами случаев нарушения порядка ценообразования по Закону г. Москвы «О государственном контроле за соблюдением порядка ценообразования и применения регулируемых цен» являются следующие:

а) завышение или занижение регулируемых и пре дельных цен, установленных надбавок

б) взимание платы за продукцию, которая в соответствии с законодательством должна быть предоставлена бесплатно;

в) непредоставление или предоставление в уменьшенном размере установленных скидок, в том числе непредоставление установленных льГОТ;

г) нарушение порядка декларирования или регистрации цен;

д) завьшение цен на продукцию, поставляемую субъектами ценообразования по государственным контрактам на поставку товаров для государственных нужд.

Как видно, нормы Закона КНР о ценах несколько отличаются по данному вопросу от положений приведенных российских правовых актов, хотя есть и много общего. В любом случае все они (и китайские, и российские) призваны максимально защитить права и законные интересы субъектов рынка в сфере добросовестной конкуренции и защиты прав потребителей в КНР и РФ.

Важно положение ст. 12 Закона о ценах, обусловленное особой ролью государства в экономике Китая, в соответствии с которым хозяйствующие субъекты при определении уровня цен должны

${ }^{8}$ Определение данных понятий см. в ст. 2 Закона г. Москвы от 28 января 2004 г. № 5 «О государственном контроле за соблюдением порядка ценообразования и применения регулируемых цен» (СПС «Гарант»). 
руководствоваться законодательством, претворяя в жизнь все запланированные и экстраординарные мероприятия, осуществляемые правительством в соответствии с положениями указанного Закона и касающиеся регулирования и определения цен.

Несмотря на то, что государство, как видно, принимает активное участие в регулировании цен, необходимо отметить, что в ст. 18 Закона КНР о ценах приводится перечень видов товаров, только в отношении которых правительство может регулировать цены или устанавливать твердые цены. Таким образом, Законом предусмотрены некоторье ограничения для правительства по этому вопросу, хотя, по мнению автора, они оставляют довольно широкий простор для усмотрения и отнесения тех или иных товаров к нижеуказанным категориям (особенно к первой). Это цены на следующие товары:

1) особо важные товары, связанные с развитием национальной экономики и жизни народа;

2) товары, связанные с нехваткой природных ресурсов;

3) товары естественных монополий.

Конкретные перечни товаров, которые относятся к вьшеуказанным пунктам Закона о ценах, определяются в подзаконных актах правительства КНР.

Так, согласно комментариям В.В. Жигулевой к Закону КНР о ценах $^{9}$, к ценам, устанавливаемым правительством, относятся, например, следующие:

1) в тяжелой промышленности и на транспорте: заводские оптовые цены на натуральный газ, нефть, грузовыс автомобили, гражданские самолеты;

2) в легкой промышленности: заводские цены на товары из золота, серебра и сплавов из них.

В свою очередь, к ценам, регулируемым правительством, относятся:

1) в сельском хозяйстве: цены на зерновые вне обязательных государственных закупок;

2) в легкой промышленности: заводские цены на сырье для некоторых синтетических волокон.

Для сравнения хотелось бы перечислить несколько видов товаров (продукции), цены на которые регулируются государственными орга-

\footnotetext{
${ }^{9} \mathrm{Cм}$. Новое законодательство Китайской Народной Республики //Экспресс-информация. 2001 . № 4/Составитель Гудошников Л.М. М.: РАН Институт Дальнего Востока. С. $84-85$.
} 
нами РФ в соответствии с упоминавшимся выше Постановлением Правительства РФ № 239:

а) продукция ядерно-топливного цикла (конкретные виды этой продукции устанавливаются отделыными нормативно-правовыми актами уполномоченных государственньх органов);

б) продукция оборонного назначения;

в) протезно-ортопедические изделия;

г) газ природный, реализуемый населению и жилищно-строительным кооперативам;

д) газ сжиженный, реализуемый населению для бытовых нужд (кроме газа для заправки автотранспортньх средств);

е) топливо твердое, топливо печное бытовое и керосин, реализуемые населению.

Как видно, данный перечень вполне соответствует видам товаров, установленным в ст. 18 Закона КНР о ценах. Необходимость государственного регулирования цен на данные товары, по мнению автора статьи, вполне обоснованна, так как это товары, которые имеют очень важное значение для государства и общества в целом, и, следовательно, цены на них должны быть разумными, предсказуемыми и находиться под постоянным контролем правительства.

Законом о ценах также устанавливается, что правительственные органы в области ценообразования должны проводить комплексные обследования уровня цен и себестоимости товаров, в отношении которых цены устанавливаются или регулируются правительством, а также, что интересно, проводить мониторинг мнений об уровне цен потребителей, производителей и прочих связанных с данным вопросом сторон. При этом все организации должны представлять для отражения реальной ситуации в данной области необходимую документацию, бухгалтерские книги и финансовые документы, а также прочие материалы (ст. 22 Закона о ценах).

Необходимо отметить важность положений ст. 243акона КНР о ценах, согласно которым государственные органы в области ценообразования после того, как будут определены установленные и регулируемые правительством цены, должны уведомить об этом потребителей и хозяйствующие субъекты, а также норм этой статьи, указываюшци, что данные цены должны регулярно пересматриваться в зависимости от развития реальной экономической ситуации и уровня рыночных цен. Также болышое значение имеет положение ст. 25 данного Закона, со- 
гласно которому потребители и хозяйствующие субъекты могут направлять предложения о пересмотре уровня установленных и регулируемых правительством цен в адрес вьшеуказанных государственных органов.

Следует отметить, что ст. 26 Закона КНР о ценах основной целью государственной макроэкономической политики провозглашает стабилизацию общего уровня рыночных цен. В гл. 4 данного Закона приводятся принципы и механизмы, при помощи которых китайское правительство стремится этого достигнуть. Так, в частности, правительственные органы в области ценообразования в целях урегулирования и стабилизации цен осуществляют мероприятия по созданию действенной системы мониторинга уровня цен, а также контролируют колебания цен на важные товары.

Показательно, что Законом КНР о ценах предусмотрены общие механизмы контроля над его реализацией. Например, в ст. 33 указывается, что «органы в области ценообразования при народных правительствах уездного уровня и вьшше осуществляют проверку и контроль за действиями в области установления цен, а также в соответствии с положениями настоящего Закона используют штрафные санкции в административном порядке в отношении противозаконных ценовых действий $\rangle^{10}$.

Интересно положение ст. 38 Закона о ценах, в которой определяется понятие «информатор». К данной категории относятся все организации и частные лица, информирующие уполномоченные государственные органы о случаях противозаконных действий в области ценообразования. Предусматривается, что деятельность информаторов должна поощряться, а данные о них сохраняться в тайне. Данный институт, насколько известно автору статьи, не знаком, к примеру, праву РФ.

Статьями 39-44 Закона КНР о ценах за нарушение его положений предусмотрены следующие виды ответственности: исправление положения, конфискация незаконно полученного дохода, штраф, приказ о приостановке хозяйственной деятельности, предупреждение, аннулирование лицензии, возврат переплаченных сумм, возмещение нанесенного ушерба. Также, согласно ст.ст. 45 и 46 Закона, на государственных служащих может быть наложена административная и даже уголовная ответственность.

${ }^{10}$ Новоезаконодательство Китайской Народной Республики //Экспресс-информация. 2001 . № 4/Составитель Гудошников Л.М. М.: РАН Ннститут Дальнего Востока. С. 79. 
Для сравнения: ст. 6 вышеназванного Закона г. Москвы устанавливает, что в случае нарушения порядка ценообразования виновные хозяйствующие субъекты, в соответствии с представлением уполномоченного органа контроля, обязаны прекратить нарушение, отменить цены, установленные с нарушением порялка ценообразования, устранить причины данного нарушения и условия, способствовавшие его совершению, а также выполнить иные действия, предусмотренные данным представлением. Кроме того, хозяйствуюшие субъекты, получившие излишшною выручку в результате данных нарушений, должны:

а) перечислить данную излипшнюю выручку в бюджет города Москвы; б) уплатить административный штраф в соответствии с КоАП РФ.

Интересная норма содержится в П. 4 ст. 6 указанного Закона, согласно которому хозяйствующий субъект, допустивший нарушение порядка ценообразования и выявивший это нарушение самостоятельно, в случае если он возвратит данные суммы потребителям (произведет перерасчет с ними) либо, в случае невозможности такого возврата (перерасчета), внесет всю указанную сумму в бюджет города Москвы, освобождастся от уплаты административного штрафа. Таким образом, по мнению автора, московский законодатель пытается способствовать тому, чтобы нарушители порядка ценообразования могли самостоятельно, по доброй воле устранить негативные последствия данного нарушения, избежав при этом экономических потерь, выражаюшихся в уплате штрафа.

Необходимо отметить, что виды ответственности за нарушение порядка ценообразования, предусмотренные Законом КНР о ценах (приказ о приостановке хозяйственной деятельности, аннулирование лицензии, уголовная ответственность государственных служащих), являются более жесткими, чем предусмотренные, например, тем же Законом г. Москвы «О государственном контроле за соблюдением порядка ценообразования и применения регулируемьх цен» (штраф). Хотя все, конечно, зависит от степени нарушения, есть и одинаковые меры ответственности, например тот же штраф, возврат переплаченных сумм, исправление положения.

Таким образом, следует отметить, что в КНР регулирование вопроса об установлении цены в договоре купли-продажи товаров осуществляется не только основным законом в данной области - Законом КНР о договорах, но и специальным законом, содержащим много довольно интересных и специфических норм, - Законом КНР о ценах. 
В праве России нет аналогичного базового закона, который бы отдельно, помимо норм Гражданского кодекса и ряда упоминавшихся иных нормативно-правовых актов, регулировал вопрос об установлении хозяйствующими субъектами цен на свои товары, в то время как в Китае он действует. Автор полагает, что факт наличия в КНР отдельного Закона о ценах обоснован спецификой всего законодательного регулирования отрасли гражданского права Китая (как и многих других отраслей жизни в этой стране), которая заключается в том, что государство принимает самое активное участие в развитии рыночной экономики страны. Автор статьи также считает, что принятие аналогичного закона в России имело бы положительный эффект для развития экономики нашей страны, при условии если российским законодателем будет использован лучший международный опыт, в частности из указанного Закона КНР о ценах. 